\title{
Psychiatric characteristics in transsexual individuals: multicentre study in four European countries ${ }^{\dagger}$
}

Gunter Heylens, Els Elaut, Baudewijntje P. C. Kreukels, Muirne C. S. Paap, Susanne Cerwenka, Hertha Richter-Appelt, Peggy T. Cohen-Kettenis, Ira R. Haraldsen and Griet De Cuypere

\section{Background}

Research into the relationship between gender identity disorder and psychiatric problems has shown contradictory results.

\section{Aims}

To investigate psychiatric problems in adults fulfilling DSM-IVTR criteria for a diagnosis of gender identity disorder.

\section{Method}

Data were collected within the European Network for the Investigation of Gender Incongruence using the Mini International Neuropsychiatric Interview - Plus and the Structured Clinical Interview for DSM-IV Axis II Disorders $(n=305)$.

\section{Results}

In $38 \%$ of the individuals with gender identity disorder a current DSM-IV-TR Axis I diagnosis was found, mainly affective disorders and anxiety disorders. Furthermore, almost $70 \%$ had a current and lifetime diagnosis. All four countries showed a similar prevalence, except for affective and anxiety disorders, and no difference was found between individuals with early-onset and late-onset disorder. An Axis I diagnosis was found in 15\% of all individuals with gender identity disorder, which is comparable to the general population.

\section{Conclusions}

People with gender identity disorder show more psychiatric problems than the general population; mostly affective and anxiety problems are found.

\section{Declaration of interest}

None.
The question of whether gender identity disorder, also known as transsexualism, goes hand in hand with psychiatric problems has been investigated in a number of studies. ${ }^{1-10}$ Still, the relationship between psychiatric morbidity and transsexualism remains a hot topic for researchers. Furthermore, the classification of gender identity disorder or transsexualism in the forthcoming DSM-5 and ICD-11 as a mental disorder is being questioned. ${ }^{11}$ The aetiology of gender identity disorder also remains unclear. The relationship between this disorder and psychiatric morbidity is of great clinical importance, as follow-up studies have demonstrated that psychiatric comorbidity is one of the major negative prognostic features for the outcome of gender reassignment surgery. ${ }^{12,13}$ Furthermore, debate on whether psychiatric comorbidity and psychosocial dysfunctioning are a consequence rather than a cause of gender identity disorder is ongoing. However, research shows contradictory findings concerning the prevalence of coexisting psychiatric problems. Some studies of psychological functioning of individuals with gender identity disorder report a high prevalence of psychiatric comorbidity, ${ }^{1-4}$ whereas other studies show results comparable with the general population. ${ }^{5-8}$ Furthermore, differences in psychiatric comorbidity and psychosocial functioning have been described between people depending on the direction of their gender reassignment (male to female $v$. female to male), and between individuals with early (pre-pubertal) onset and late (post-pubertal) onset gender identity disorder; most studies found more psychological problems in male to female reassignment, ${ }^{2,7-9}$ whereas Bodlund et al reported more personality disorders in people who had undergone female to male procedures. ${ }^{10}$ Although there is no single, generally accepted definition of early- and late-onset transsexual development as yet, ${ }^{14}$ some studies have found that

†See editorial, pp. 96-97, this issue. people with late-onset transsexualism showed more psychiatric problems than those with early-onset transsexualism. ${ }^{15}$

The contradictory findings of the aforementioned studies are due partially to methodological differences, different ways of collecting data and differences in chosen instruments. Moreover, some studies suffer from serious flaws such as selection bias. As long as 30 years ago, Lothstein criticised the lack of systematic assessment and objective data collection. ${ }^{16}$ During recent decades the quality of research on gender identity disorder has improved substantially, resulting in larger and more reliable data-sets; nevertheless, large, prospective multicentre European studies with systematic data collection are still lacking. Our study is intended to fill this gap as part of the European Network for the Investigation of Gender Incongruence (ENIGI), an international collaboration initiated to set up diagnostic protocols and assessment batteries. ${ }^{17}$ The major aim of our study was to investigate the prevalence of psychiatric problems in individuals with gender identity disorder seeking gender reassignment therapy. We compared different groups in terms of direction of gender reassignment, time of onset, comparison with the general population and clinic attended.

\section{Method}

Four countries participate in the ENIGI network: The Netherlands, Belgium, Germany and Norway. ${ }^{17}$ Data were collected in Amsterdam, Ghent, Hamburg and Oslo between January 2007 and October 2010. The study was approved by the local ethics committees.

\section{Participants}

Adults seeking gender reassignment therapy and surgery at the four gender clinics were asked to participate. Patients were 
excluded from the study if they were experiencing psychosis at the time of assessment, were under 17 years old or had insufficient command of the language of the country in which they lived. Both self- administered questionnaires and clinical interviews were used in all gender identity clinics. All data were collected within the first 6 months of the diagnostic phase. All clinicians involved were trained psychologists or psychiatrists with experience in the field of gender identity disorder.

\section{Measures}

\section{Gender identity disorder}

Clinicians used a self-constructed scoring sheet with 23 items based on the DSM-IV-TR symptoms and diagnostic criteria for gender identity disorder and gender identity disorder in childhood (see the online supplement to this paper). ${ }^{18,19}$ These items consisted of a combination of a symptom and an 'aspect' (severity, onset, duration, frequency and persistence); see Paap et al for a detailed analysis of this instrument). ${ }^{18}$

\section{Gender dysphoria}

The Utrecht Gender Dysphoria Scale (UGDS) was used to measure the degree of experienced gender dysphoria. ${ }^{20}$

\section{Axis I disorders}

The Mini International Neuropsychiatric Interview - Plus version 5.0.0 (MINI-Plus) was used to measure Axis I diagnoses. ${ }^{21}$ This is a short, structured diagnostic interview for DSM-IV psychiatric disorders, allowing clinicians to assess Axis I diagnoses at the time of the interview ('current diagnosis') and disorders that have a longer history ('current and lifetime diagnosis').

\section{Axis II disorders}

The Structured Clinical Interview for DSM-IV Axis II Personality Disorders (SCID-II) was used to assess Axis II diagnoses; this is a semi-structured clinical interview. ${ }^{22}$ For logistic reasons the SCID-II was not administered in The Netherlands. As a consequence, results regarding Axis II disorders are based on data from Ghent, Hamburg and Oslo only.

\section{Terminology}

In this paper we use the term 'gender identity disorder' only when we refer to the clinical diagnosis.

\section{Onset}

Disorders were labelled as 'early-onset' when they met both criteria A and B for a diagnosis of gender identity disorder in childhood (see the online supplement); if they fulfilled neither criterion, they were categorised as 'late-onset' gender identity disorder. A residual group comprised cases fulfilling only one criterion (A or B). ${ }^{14}$

\section{Statistical analysis}

Chi-squared tests were used to test for differences in the occurrence of psychiatric problems among groups. The variables we tested included: gender (male to female $v$. female to male), country (Belgium, Germany, The Netherlands, Norway) and onset age (early $v$. late). Analyses were performed separately for Axis I and Axis II disorders. Axis I disorders were divided into six clusters: affective, anxiety, eating, substance-related, psychotic and other disorders. If marked differences were found for a certain group of disorders, a logistic regression analysis was performed with the psychiatric disorder as dependent variable and the group variables as independent variables to gain more insight in the relative contributions of each of the group variables in predicting whether or not the disorder was present. All analyses were conducted using SPSS version 16.0.1 for Windows.

\section{Results}

During the inclusion period 846 persons applied for treatment at the four gender clinics. Of these applicants, 125 were excluded from the study owing to an insufficient command of the language of the questionnaires $(n=57,46 \%)$, refusal to participate $(n=37$, $30 \%)$, clear psychotic symptoms at the time of application $(n=16$, $13 \%)$ or for other reasons $(n=15,11 \%)$. Consequently, 721 individuals completed at least one diagnostic instrument (Fig. 1). Some instruments were not completed owing to withdrawal (failing to attend consultations) or refusal to participate in the clinical interviews. Sample characteristics with regard to gender ratio, onset age and age at assessment are shown in Table 1. At the end of the inclusion period 305 individuals fulfilled criteria for early- or late-onset gender identity disorder and had been assessed by means of the MINI-Plus and/or the SCID-II. Fortyone applicants did not fulfil the gender identity disorder criteria and 140 were categorised into the residual gender identity disorder group. Of our final sample of 305 participants, 182 (59.7\%) requested male to female and $123(40.3 \%)$ female to male reassignment.

\section{Axis I disorders}

Almost $70 \%$ of the final sample of 305 participants showed one or more Axis I disorders current and lifetime (Table 2), mostly affective and anxiety disorders (respectively 60\% and 28\%). Prevalence rates were similar in both genders. No association

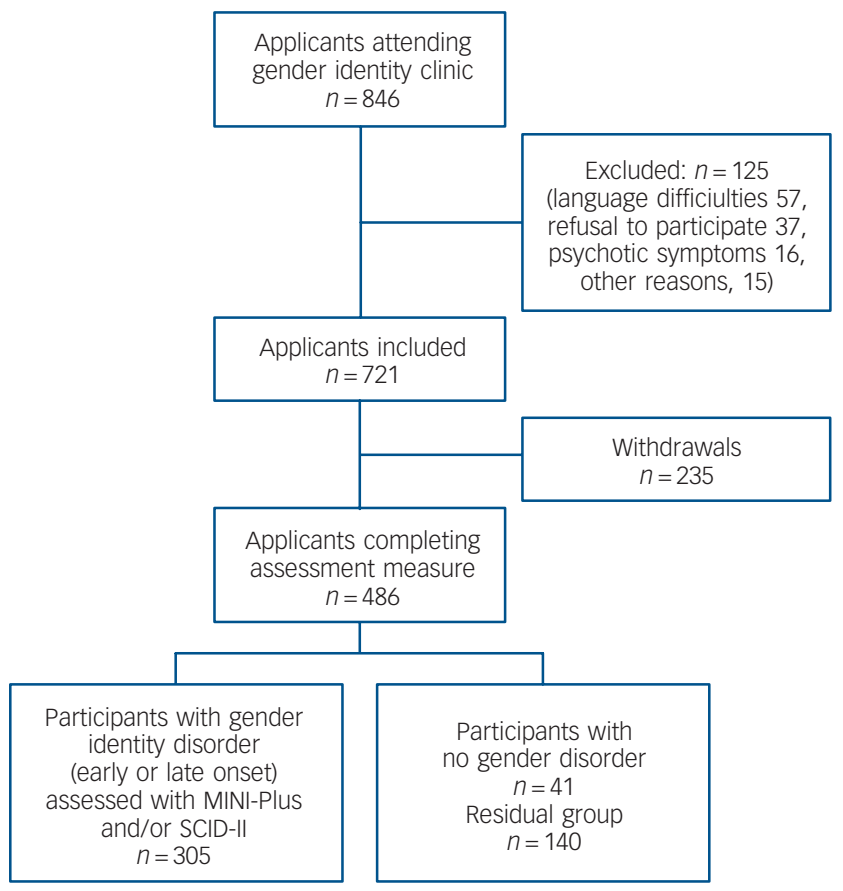

Fig. 1 Selection procedure and numbers of participants: early onset (fulfilled both DSM-IV criteria A and B in childhood); late onset (neither DSM-IV criterion); residual group (one criterion). MINI-Plus, Mini International Neuropsychiatric Interview - Plus; SCID-II, Structured Clinical Interview for DSM Axis II Disorders. 


\begin{tabular}{|c|c|c|c|c|c|c|}
\hline & $\begin{array}{l}\text { Belgium } \\
n=63\end{array}$ & $\begin{array}{l}\text { Germany } \\
n=57\end{array}$ & $\begin{array}{l}\text { The Netherlands } \\
\qquad n=147\end{array}$ & $\begin{array}{c}\text { Norway } \\
n=38\end{array}$ & $\begin{array}{l}\text { All countries } \\
\quad n=305\end{array}$ & $P^{a}$ \\
\hline Gender ratio (MtF:FtM) & $2.15: 1$ & $1.04: 1$ & $2.27: 1$ & $0.47: 1$ & $1.48: 1$ & $<0.0001$ \\
\hline $\mathrm{MtF}, n$ & 43 & 29 & 102 & 8 & 182 & \\
\hline FtM, $n$ & 20 & 28 & 45 & 30 & 123 & \\
\hline \multicolumn{7}{|l|}{ Age at onset, $n$ (\%) } \\
\hline \multicolumn{7}{|l|}{ Early onset } \\
\hline MtF & $25(58)$ & $13(45)$ & $50(49)$ & $4(50)$ & $92(51)$ & \\
\hline FtM & $20(100)$ & $24(86)$ & $37(82)$ & $29(97)$ & $110(89)$ & \\
\hline \multicolumn{7}{|l|}{ Late onset } \\
\hline MtF & & & & & $90(49)$ & $0.01^{\mathrm{b}}$ \\
\hline FtM & & & & & $13(11)$ & \\
\hline \multicolumn{7}{|c|}{ Age at assessment, years: mean (s.d.) } \\
\hline MtF & $35.6(9.9)$ & $34.6(11.8)$ & $36.5(13.2)$ & $21.6(3.7)$ & $35.3(12.3)$ & $<0.0001^{\circ}$ \\
\hline FtM & $29.9(9.0)$ & $29.2(10.8)$ & $31.2(11.3)$ & $22.8(5.4)$ & $28.5(10.1)$ & \\
\hline \multicolumn{7}{|c|}{$\begin{array}{l}\text { FtM, female to male reassignment; MtF, male to female reassignment. } \\
\text { a. Differences between countries for the MtF plus FtM groups combined. } \\
\text { b. Early } v \text {. late onset. } \\
\text { c. Kruskal-Wallis test. }\end{array}$} \\
\hline
\end{tabular}

was found between the presence of a current and lifetime Axis I diagnosis and age at assessment $(P=0.189)$. Patients with a current Axis I diagnosis were younger than those without one $(P=0.017)$. The degree of gender dysphoria was not associated with the presence of an Axis I diagnosis in general, neither was it associated with specific diagnoses such as depressive episode, panic attack, agoraphobia or substance-related problems. In the total cohort there was no difference in the prevalence of Axis I disorders between the early- and late-onset subgroups and this was true for both genders $(P=0.6$ for the total cohort, $P=0.4$ for the male to female group and $P=0.9$ for the female to male group).

With regard to the prevalence of Axis I disorders among the four countries, we found a difference between countries among male to female transsexual subgroups, both for current and current and lifetime diagnoses $(P=0.001$ for current diagnoses,
$P=0.009$ for current and lifetime diagnoses). Male to female transsexual patients in Germany and Norway showed higher prevalence rates compared with those in Belgium and The Netherlands. No difference was found between the female to male transsexual subgroups. Differences between countries were found for the affective cluster $(P=0.001$ for both current and lifetime and current) and anxiety cluster $(P=0.029$ for current and lifetime, $P=0.028$ for current). In Germany, up to $80 \%$ of participants with the diagnosis of gender identity disorder showed affective symptoms currently or in the past compared with approximately $50 \%$ in the other countries. The Dutch patients had fewer anxiety symptoms currently or in the past compared with the other countries (20\% rather than $30-40 \%$ ).

In almost $30 \%$ of the participants suicide risk was identified (meaning they had suicidal ideations and/or plans during the

\begin{tabular}{|c|c|c|c|c|c|c|}
\hline & Belgium & Germany & The Netherlands & Norway & All countries & $P^{a}$ \\
\hline \multicolumn{7}{|l|}{ Gender, $n$} \\
\hline $\mathrm{MtF}$ & 43 & 28 & 102 & 7 & 180 & \\
\hline FtM & 20 & 25 & 45 & 28 & 118 & \\
\hline \multicolumn{7}{|c|}{ One or more Axis I disorders, $n$ (\%) } \\
\hline Current & & & & & & NS \\
\hline MtF & $13(30)$ & $15(54)$ & $34(33)$ & $7(100)$ & $69(38)$ & \\
\hline FtM & $8(40)$ & $12(48)$ & $16(36)$ & $8(29)$ & $44(37)$ & \\
\hline Current and lifetime & & & & & & NS \\
\hline MtF & $25(58)$ & $25(89)$ & $66(65)$ & $7(100)$ & $123(68)$ & \\
\hline FtM & $19(95)$ & $18(72)$ & $30(67)$ & $17(61)$ & $84(71)$ & \\
\hline \multicolumn{7}{|l|}{ Affective disorders, $n$ (\%) } \\
\hline Current & $8(13)$ & $21(40)$ & $37(25)$ & $15(43)$ & $81(27)$ & 0.005 \\
\hline Current and lifetime & $29(46)$ & $43(81)$ & $88(60)$ & $19(54)$ & $179(60)$ & $<0.0001$ \\
\hline \multicolumn{7}{|l|}{ Anxiety disorders, $n$ (\%) } \\
\hline Current & $14(22)$ & $13(24)$ & $15(10)$ & $8(23)$ & $50(17)$ & 0.035 \\
\hline Current and lifetime & $24(38)$ & $20(38)$ & $31(21)$ & $10(29)$ & $85(28)$ & 0.020 \\
\hline \multicolumn{7}{|c|}{ Substance-related disorders, $n$ (\%) } \\
\hline Current & $4(6)$ & $4(8)$ & $14(10)$ & $2(6)$ & $24(8)$ & NS \\
\hline Current and lifetime & $16(25)$ & $6(11)$ & $23(16)$ & $2(6)$ & $47(16)$ & 0.028 \\
\hline \multicolumn{7}{|l|}{ Eating disorders, $n$ (\%) } \\
\hline Current & $1(2)$ & $1(2)$ & $0(0)$ & $0(0)$ & $2(1)$ & NS \\
\hline Current and lifetime & $1(2)$ & $2(4)$ & $1(1)$ & $2(6)$ & $6(2)$ & NS \\
\hline \multicolumn{7}{|l|}{ Psychotic disorders, $n$ (\%) } \\
\hline Current and lifetime & $0(0)$ & $0(0)$ & $3(2)$ & $1(3)$ & $4(1)$ & NS \\
\hline
\end{tabular}


preceding month and/or had ever attempted suicide). Female to male and male to female subgroups reported similar degrees of suicidal ideation $(P=0.671)$. There was no difference between the early- and late-onset groups $(P=0.165)$. Suicide risk was not associated with having an Axis II diagnosis $(P=0.536)$. No difference was found between the four countries.

A logistic regression was performed with 'affective disorder' as a dependent variable to gain a better understanding of the factors that might be associated with the differences between the countries. We chose to retain only significant effects in the final model. A forward step-wise strategy was used, adding the following variables one at a time: assessment age $(\leqslant 30$ years $v$. $>30$ years), onset age, gender and country. Interaction effects between variables were also calculated and added to the model. Our final model contained the variables country, gender and country $\times$ gender. The main effects of country and gender were no longer significant when the interaction effect was added. The interaction effect indicated that people undergoing male to female reassignment were more likely to have an affective disorder in Germany (odds ratio $(\mathrm{OR})=11.4, P=0.013$ ) and Norway $(\mathrm{OR}=20.0, P=0.014)$; Belgium was used as the reference category. No difference between the countries was found for the female to male subgroups.

\section{Axis II disorders}

Schizoid, avoidant and borderline personality disorders were most prevalent, in $5 \%, 4 \%$ and $7 \%$ of our sample respectively. The overall prevalence rate for personality disorders was $15 \%$ (Table 3). No difference was found between the male to female transsexual group ( $12 \%$ had one or more personality disorders) and the female to male group (one or more personality disorders in $18 \%$ ). The Axis II prevalence rates were similar in the three countries. In the total cohort and in the male to female subgroup there was no difference in prevalence of Axis II disorders between the early- and late-onset groups. In the female to male group, individuals with late-onset disorder had significantly more personality disorders $(P=0.003)$. Individuals showing borderline personality disorder were younger at the time of application to the clinic $(P=0.009)$; this group also showed a trend towards stronger gender dysphoria $(P=0.073)$. Personality disorders were also clustered in three groups. Cluster $C$ disorders were most common (63\% of all personality disorders), followed by cluster B (45\%) and cluster A (41\%). No difference was found between the four countries with regard to clusters of personality disorders.

\section{Discussion}

Overall, we found that Axis I disorders were more common in applicants for treatment of gender identity disorder compared with the general populations of the participating countries. ${ }^{23-26}$ On closer inspection we found that this difference was mainly due to affective and anxiety disorders, with the gender identity disorder group showing higher rates than the general population. This was the case in all four countries and for both male to female and female to male reassignment groups. Other Axis I clusters were found to be equally prevalent compared with the general population. Although the prevalence rates of affective and anxiety disorders in the general population differed slightly between the four countries, this cannot fully account for the differences we found in our population. A new study would be needed to assess which factors (e.g. patient and clinician characteristics or social differences among the countries) might explain these findings.

The incongruence between gender identity and social life and/ or bodily characteristics experienced by individuals diagnosed with gender identity disorder can cause much distress that may lead to affective and anxiety problems and even disorders. Follow-up studies often show a resolution of depressive and anxious symptoms throughout the treatment process. ${ }^{27-29}$ Furthermore, the phenomenon of 'minority stress' can also explain the high prevalence of affective disorders. Social discrimination and stigmatisation may cause a diminished quality of life, particularly with regard to mental health. ${ }^{30}$

The findings with regard to the prevalence of suicide risk confirm results on this topic. ${ }^{8,31,32}$ Terada et al reported that the high prevalence of suicidality in their gender identity disorder population was not related to psychiatric comorbidity. ${ }^{32}$ This suggests that gender identity disorder is an independent risk factor for suicidal behaviour and this could be interpreted as an (inappropriate) coping strategy. ${ }^{31}$ In a report on suicide and suicide risk in transgender populations, Haas et al emphasised high suicide and suicide attempt rates. ${ }^{32}$ Besides the high prevalence of depression, anxiety and substance misuse in these populations, factors such as parental rejection and discrimination are linked to elevated risk of suicidal behaviour. A longitudinal study in lesbian, gay, bisexual and transgender youth by Liu \& Mustanski showed that childhood gender non-conformity and victimisation were associated with increased risk of self-harm and suicidal ideation. ${ }^{33}$ In our study, suicidality was assessed using the MINI-Plus interview, which was also used to measure Axis I disorders; we therefore could not investigate whether there was an association between suicide risk and having an Axis I disorder. No association was found between suicide risk and the presence of personality disorder, which again illustrates that gender identity disorder may be an independent risk factor for suicidality.

Major psychiatric disorders such as bipolar disorder or psychosis were rarely found and did not exceed prevalence in the general population. ${ }^{23-25}$ Since the presence of psychosis was explicitly defined as an exclusion criterion, there was a severe bias. However, the low number of applicants (16 of 846) excluded for this reason does not suggest that our findings were a severe underestimation of the true prevalence.

Comparison between the prevalence of Axis I disorders in our study and rates in the general population should be interpreted with caution: epidemiological studies in different countries use

\begin{tabular}{|c|c|c|c|c|c|}
\hline & $\begin{array}{c}\text { Belgium } \\
n=60\end{array}$ & $\begin{array}{c}\text { Germany } \\
n=55\end{array}$ & $\begin{array}{c}\text { Norway } \\
n=29\end{array}$ & $\begin{array}{c}\text { All countries } \\
n=144\end{array}$ & $P^{\mathrm{a}}$ \\
\hline One or more Axis II disorders, $n$ (\%) & $10(17)$ & $10(18)$ & $2(7)$ & $22(15)$ & NS \\
\hline Cluster A & $4(7)$ & $3(6)$ & $2(7)$ & $9(6)$ & NS \\
\hline Cluster B & $5(8)$ & $3(6)$ & $2(7)$ & $10(7)$ & NS \\
\hline Cluster C & $8(13)$ & $6(11)$ & $0(0)$ & $14(10)$ & NS \\
\hline
\end{tabular}


different instruments and sometimes data on certain clinical categories are simply missing. Still, it is clear that the prevalence of both current and current and lifetime Axis I disorders in our study population is higher than in the general population of all four countries. This difference is mainly due to the high prevalence (up to three times higher compared with the general population) of affective and anxiety disorders. For example, current affective problems occur at rates between 6\% (Belgium and The Netherlands) and 11-12\% (Germany and Norway) in the general population, whereas in our sample prevalence rates ranged from $13 \%$ and 25\% (Belgium and The Netherlands) to $40 \%$ and $35 \%$ (Germany and Norway). ${ }^{23-26}$ The European Study of the Epidemiology of Mental Disorders (ESEMeD) project, conducted in six European countries (including Belgium, Germany and The Netherlands), found a lifetime prevalence of any mental disorder in $25 \%$ of respondents, a much lower percentage than in our cohort (see above). Any mood disorder and any anxiety disorder were found in $14 \%$. Women were twice as likely to have any mental problem compared with men, especially with regard to mood and anxiety disorders which occurred two to three times more frequently in women. ${ }^{34}$ In our sample Axis I disorders were equally distributed in the male to female and female to male reassignment subgroups, except in Norway where they were more common in the female to male group.

The low degree of psychopathology with regard to personality disorders replicates the findings of some earlier studies, ${ }^{35}$ but contradicts the high prevalence of such disorders found in similar studies by Hepp et al and Madeddu et al: both studies also used the SCID-II interview and included only people with gender identity disorder, ${ }^{4,36}$ as we did in our study. A potential explanation for our findings contradicting those of Hepp et al and Madeddu et al could be that some individuals with a personality disorder were more reluctant to participate in our study owing to a lack of confidence in professional caregivers. Our findings accord with prevalence rates of personality disorders in the general population of Germany $(10.0 \%)$ and Norway (13.4\%)..$^{37,38}$ No information on prevalence exists for Belgium; however, in The Netherlands the prevalence is $13.5 \% .{ }^{39}$ Moreover, the distribution in clusters of personality disorders found in this study resembles the distribution found in epidemiological studies in Germany, Norway and The Netherlands. ${ }^{37-39}$ Statistics on the Axis II data should be interpreted with caution, owing to the low numbers in most disorder categories.

In contrast to some reports (and the general impression among clinicians) that individuals with late-onset gender identity disorder are more psychiatrically affected, ${ }^{15}$ no difference concerning psychiatric comorbidity, whether Axis I and Axis II, was found between individuals with early- $v$. late-onset disorder. The only exception was among the female to male reassignment group, in which those with late-onset disorder showed more Axis II problems than those with early-onset disorder, but numbers were very small (only four individuals in the late-onset group) and this finding needs to be replicated in a larger study.

In conclusion, our findings show that individuals with gender identity disorder have more psychiatric problems than the general population: mostly these are affective and anxiety problems. Although more decisive conclusions cannot be drawn owing to the cross-sectional design of our study, psychopathological symptoms seem to be closely related to the individual's longstanding and strongly felt identification with the other gender. Further research should focus on long-term follow-up studies using standardised diagnostic and therapeutic protocols in order to determine whether the Axis I diagnosis rate decreases with treatment and whether such a decrease manifests in any particular subcategory of patient. This might lead to a better understanding of the nature of gender identity disorder and of the psychiatric symptoms experienced in connection with this disorder.

\section{Acknowledgements}

The authors wish to thank all clinicians who participated in this study, collected the data and were responsible for the data entry

Gunter Heylens, MD, Els Elaut, MSc, Department of Sexology and Gende Problems, University Hospital Ghent, Belgium; Baudewijntje P. C. Kreukels, PhD, Department of Medical Psychology, VU University Hospital, Amsterdam, The Netherlands; Muirne C. S. Paap, PhD, Department of Research Methodology, Measurement and Data Analysis, Behavioural Sciences, Susanne Cerwenka, Mr.Sc Hertha Richter-Appelt, PhD, Department of Sex Research and Forensic Psychiatry, University Medical Centre Hamburg-Eppendorf, Germany; Peggy T. Cohen-Kettenis, PhD, Department of Medical Psychology, VU University Hospital Amsterdam, The Netherlands; Ira R. Haraldsen, MD, PhD, Department of Neuropsychiatry and Psychosomatic Medicine, Rikshospitalet Oslo, Norway; Griet De Cuypere, MD, PhD, Department of Sexology and Gender Problems, University Hospital Ghent, Belgium

Correspondence: Gunter Heylens, Department of Sexology and Gender Problems, University Hospital Ghent De Pintelaan 185, 9000 Ghent, Belgium. Email: gunter.heylens@uzgent.be

First received 18 Oct 2012, final revision 31 Jan 2013, accepted 4 Mar 2013

\section{References}

1 Verschoor AM, Poortinga J. Psychosocial differences between Dutch male and female transsexuals. Arch Sex Behav 1988; 17: 173-8.

2 De Cuypere G, Jannes C, Rubens R. Psychosocial functioning of transsexuals in Belgium. Acta Psychiatr Scand 1995; 91: 180-4.

3 A Campo JM, Nijman H, Merckelbach H, Evers C. Psychiatric comorbidity of gender identity disorders: a survey among Dutch psychiatrists. Am J Psychiatry 2003; 160: 1332-6.

4 Hepp U, Kraemer B, Schnyder U, Miller N, Delsignore A. Psychiatric comorbidity in gender identity disorder. J Psychosom Res 2005; 58 : 259-61.

5 Cole CM, O'Boyle M, Emory LE, Meyer WJ. Comorbidity of gender dysphoria and other major psychiatric diagnoses. Arch Sex Behav 1997; 26: 13-26.

6 Haraldsen IR, Dahl AA. Symptom profiles of gender dysphoric patients of transsexual type compared to patients with personality disorders and healthy adults. Acta Psychiatr Scand 2000; 102: 276-81.

7 Gomez-Gil E, Trilla A, Salamero M, Godas T, Valdes M. Sociodemographic, clinical, and psychiatric characteristics of transsexuals from Spain. Arch Sex Behav 2009; 38: 378-92.

8 Hoshiai M, Matsumoto $Y$, Sato T, Ohnishi M, Okabe N, Kishimoto Y, et al. Psychosomatic comorbidity among patients with gender identity disorder. Psychiatry Clin Neurosci 2010; 64: 514-9.

9 Landen M, Walinder J, Lundstrom B. Clinical characteristics of a total cohort of female and male applicants for sex reassignment: a descriptive study. Acta Psychiatr Scand 1998; 97: 198-4.

10 Bodlund $\mathrm{O}$, Kullgren G, Sundbom E, Hojerback T. Personality traits and disorders among transsexuals. Acta Psychiatr Scand 1993; 88: 322-7.

11 Meyer-Bahlburg HFL. From mental disorder to iatrogenic hypogonadism: dilemmas in conceptualising gender identity variants as psychiatric conditions. Arch Sex Behav 2010; 39: 461-76.

12 De Cuypere G, Vercruysse $\mathrm{H}$. Eligibility and readiness criteria for sex reassignment surgery: recommendations for revision of the WPATH standards of care. Int J Transgender 2011; 11: 194-205.

13 Dhejne C, Lichtenstein P, Boman M, Johansson ALV, Langstrom N, Landen M. Long-term follow-up of transsexual persons undergoing sex reassignment surgery: cohort study in Sweden. PIOS ONE 2011; 6: 1-8.

14 Nieder TO, Herff M, Cerwenka S, Preuss WF, Cohen-Kettenis PT, De Cuypere $\mathrm{G}$, et al. Age of onset and sexual orientation in transsexual males and females. J Sex Med 2011; 8: 783-91.

15 Smith YLS, van Goozen SHM, Kuiper AJ, Cohen-Kettenis PT. Transsexual subtypes: clinical and theoretical significance. Psychiatry Res 2005; 137 $151-60$.

16 Lothstein LM. Psychological testing with transsexuals: a 30-year review. J Pers Assess 1984; 48: 500-7.

17 Kreukels BP, Haraldsen IR, De Cuypere G, Richter-Appelt H, Gijs L, Cohen-Kettenis PT. A European network for the investigation of gender incongruence: the ENIGI initiative. Eur Psychiatry 2012; 27: 445-50. 
18 Paap MCS, Kreukels BPC, Cohen-Kettenis PT, Richter-Appelt H, De Cuypere G, Haraldsen IR. Assessing the utility of diagnostic criteria: a multisite study on gender identity disorder. J Sex Med 2011; 8: 180-90.

19 American Psychiatric Association. Diagnostic and Statistical Manual of Mental Disorders (4th edn, Text Revision) (DSM-IV-TR). APA, 2000.

20 Cohen-Kettenis $\mathrm{P}$, Van Goozen SH. Sex reassignment of adolescent transsexuals: a follow-up study. J Am Acad Child Adolesc Psychiatry 1997; 36: 263-71.

21 Sheehan DV, Lecrubier $\mathrm{Y}$, Sheehan $\mathrm{KH}$, Amorim $\mathrm{P}$, Janavs J, Weiller $\mathrm{E}$, et al The Mini-International Neuropsychiatric Interview (MINI): the development and validation of a structured diagnostic psychiatric interview for DSM-IV and ICD-10. J Clin Psychiatry 1998; 59 (suppl 20): 22-33.

22 First MB, Gibbon M, Spitzer RL, Williams JBW, Benjamin L. Structured Clinical Interview for DSM-IV Axis II Personality Disorders (SCID-II). American Psychiatric Press, 1997.

23 Bruffaerts R, Bonnewyn A, Van Oyen H, Demarest S, Demyttenaere K. Prevalence of pure and comorbid mental disorders in Belgium. Rev Med Liege 2003; 58: 741-50.

24 Jacobi F, Wittchen $\mathrm{HU}$, Holting $\mathrm{C}$, Hofler M, Pfister $\mathrm{H}$, Muller $\mathrm{N}$, et al. Prevalence, comorbidity and correlates of mental disorders in the general population: results from the German Health Interview and Examination Survey (GHS). Psychol Med 2004; 34: 597-611.

25 De Graaf R, Ten Have C, van Gool S, van Dorsselaer S. Prevalence of mental disorders, and trends from 1996 to 2009; results from NEMESIS-2. Tijdschr Psychiatr 2012; 54: 27-38.

26 Kringlen E, Torgersen S, Cramer V. A Norwegian psychiatric epidemiological study. Am J Psychiatry 2001; 158: 1091-8.

27 Mate-Kole C, Freschi M, Robin A. Aspects of psychiatric symptoms at different stages in the treatment of transsexualism. Br J Psychiatry 1988; 152: $550-3$.

28 Mate-Kole C, Freschi M, Robin A. A controlled study of psychological and social change after surgical gender reassignment in selected male transsexuals. Br J Psychiatry 1990; 157: 261-4.
29 Gomez-Gil E, Vidal-Hagemeijer A, Salamero M. MMPI-2 characteristics of transsexuals requesting sex reassignment: comparison of patients in prehormonal and presurgical phases. J Pers Assess 2008; 90: 368-74.

30 Newfield E, Hart S, Dibble S, Kohler L. Female-to-male transsgender quality of life. Qual Life Res 2006; 15: 1447-57.

31 Terada S, Matsumoto Y, Sato T, Okabe N, Kishimoto Y, Uchitomi Y. Suicidal ideation among patients with gender identity disorder. Psychiatry Res 2011; 190: 159-62.

32 Haas AP, Eliason M, Mays VM, Mathy RM, Cochran SD, D'Augelli AR, et al. Suicide and suicide risk in lesbian, gay, bisexual, and transgender populations: review and recommendations. J Homosex 2011; 58: 10-51.

33 Liu RT, Mustanski B. Suicidal ideation and self-harm in lesbian, gay, bisexual and transgender youth. Am J Prev Med 2012; 42: 221-8.

34 Alonso J, Angermeyer MC, Bernert S, Bruffaerts R, Brugha TS, Bryson $\mathrm{H}$, et al. Prevalence of mental disorders in Europe: results from the European Study of the Epidemiology of Mental Disorders (ESEMeD). Acta Psychiatr Scand Suppl 2004; 420: 21-7.

35 Miach PP, Berah EF, Butcher JN, Rouse S. Utility of the MMPI-2 in assessing gender dysphoric patients. J Pers Assess 2000; 75: 268-79.

36 Madeddu F, Prunas A, Hartmann D. Prevalence of Axis II disorders in a sample of clients undertaking psychiatric evaluation for sex reassignment surgery. Psychiatr Q 2009; 80: 261-7.

37 Maier W, Lichtermann D, Klinger T, Heun R, Hallmayer J. Prevalences of personality disorder (DSM-III-R) in the community. J Pers Disord 1992; 6 : 187-96.

38 Torgersen S, Kringlen E, Cramer V. The prevalence of personality disorders in a community sample. Arch Gen Psychiatry 2001; 58: 590-6.

40 Landelijke Stuurgroep Multidisciplinaire Richtlijnontwikkeling in de GGZ. Multidisciplinaire Richtlijn Persoonlijkheidsstoornissen 2008. Trimbos Institute, 2008.

\section{reflection}

\section{On Nikolai Gogol's Diary of a Madman}

\section{Rachel Upthegrove}

It is not uncommon for us psychiatrists to spend time questioning our diagnostic categories, constructs and presumptions. While reading draft DSM-5 and debates around ICD-11, one might be forgiven for thinking we are very far from achieving diagnostic criteria of mental illness that are anything near accurate. In times of doubt, I advise a dip into Gogol. Diary of a Madman reminds us that, although we may struggle to capture the entirety of mental illness or draw the nuanced boundaries, we can at least be clear on what constitutes psychosis. On reading this text I am reminded then that the recognition of psychopathology is far easier than definition, and has been for centuries.

Nikolai Gogol was born in 1809 in the Ukraine and spent his early adulthood as clerk in the burgeoning government ministries. His own mental illness, with features of religious mania and depressive stupor, began after the composition of Diary and led to his untimely death in 1852. Thus, it is his own observation (or indeed perhaps untreated psychosis) on which Gogol draws to allow such accuracy of portrayal. We are treated not only to auditory verbal hallucinations in the form of talking dogs, veridical in nature, but delusional mood and primary delusion: 'I couldn't get that Spanish business out of my head. How could a woman inherit the throne?', followed by 'Today is a day of triumph, There is a king of Spain. He has been found at last. That king is me. I only discovered this today. Frankly, it all came to me in a flash. I don't understand why, but before this revelation everything was enveloped in a mist...

The portrayal of the unshakable nature of delusions, evidence gathered to reinforce belief and evidence disregarded that challenges, is striking and maps neatly on to current cognitive models of delusional formation. On transport to the asylum our protagonist retorts: 'I think I'm safe in hazarding a guess that I've fallen into the hands of the Inquisition, and the person I thought was a minister of state was really the Grand Inquisitor'.

At 20 short pages this story is readily accessible, even though written in a different language, set in a culture far from our own and nearly two centuries old. I use it to teach students. I ask them to identify symptoms, discuss how the diary format enables us to have direct access to subjective experience and reflect on treatment of mental illness in the past. This is much more illustrative than any textbook. Above all, I read it to reaffirm that although we have some way to go in psychiatry we are, after all, on the right track. 